\title{
The Endoparasitic Nematophagous Fungus Meria coniospora Infects Nematodes Specifically at the Chemosensory Organs
}

\author{
By HANS-BÖRJE JANSSON* AND BIRGIT NORDBRING-HERTZ \\ University of Lund, Department of Microbial Ecology, Ecology Building, Helgonavägen 5, \\ S-223 62 Lund, Sweden
}

(Received 28 August 1982; revised 5 October 1982)

\begin{abstract}
Conidia of the endoparasitic fungus Meria coniospora infected the bacterial-feeding nematode Panagrellus redivivus at specific sites, namely the mouth region and in male nematodes also in the tail. Plant-parasitic nematodes were also infected in other parts of the body. The specific infection sites in $P$. redivivus were the sensory organs, which are the sites of chemoreception. Blocking of chemoreceptors by adhered conidia of $M$. coniospora caused a complete loss of the ability of nematodes to be attracted to different sources of attractants. Inhibition of conidial adhesion by means of sugar haptens suggested a lectin-carbohydrate interaction. Out of 21 sugars only $\mathrm{N}$-acetylneuraminic acid inhibited the adhesion, indicating the importance of sialic acids in the infection process. Reduction of conidial adhesion by treatment of nematodes with neuraminidase further supported this view.
\end{abstract}

\section{INTRODUCTION}

Nematophagous fungi comprise the nematode-trapping species and the endoparasitic fungi (Barron, 1977). Some nematode-trapping fungi produce traps with a mechanical function, while other fungi bear different kinds of adhesive traps. The endoparasitic fungi, on the other hand, infect nematodes with their conidia which are either ingested, e.g. Harposporium sp., or adhere to the cuticle of the worms, e.g. Meria coniospora, Nematoctonus sp., Cephalosporum sp. (Barron, 1977).

The mycelia of a majority of nematophagous fungi attract both bacterial-feeding and plantparasitic nematodes (Jansson \& Nordbring-Hertz, 1979, 1980). The presence of traps on the mycelia increases the ability of the fungi to attract nematodes (Field \& Webster, 1977; Jansson, 1983). Furthermore, adhesive conidia of endoparasitic fungi attract nematodes, whereas nonadhesive do not (Jansson, 1982).

Most nematophagous fungi seem to be able to infect nematodes over the whole nematode cuticle (Barron, 1977; Nordbring-Hertz \& Stålhammar-Carlemalm, 1978). Infection by $M$. coniospora, on the other hand, frequently takes place in the mouth region (Barron, 1977; Jansson, 1982). An interesting fact is that the sensory organs of the nematodes are situated in the papillae around the mouth (Ward, 1978; Wright, 1980; Coomans \& De Grisse, 1981). The sensory organs contain the receptors responsible for nematode chemotaxis (e.g. Ward, 1978). Whether there is a connection between chemoattraction of nematodes and adhesion of conidia to the buccal cavity of the worms is not known.

In the nematode-trapping fungus Arthrobotrys oligospora, the adhesive network traps bear a lectin which binds specifically to a sugar residue on the nematode surface (Nordbring-Hertz \& Mattiasson, 1979). A similar mechanism is indicated in another nematode-trapping fungus, Dactylaria candida, producing adhesive knobs (Nordbring-Hertz et al., 1982). In consequence, the question arose whether a corresponding interrelationship also exists in the endoparasitic fungi with adhesive conidia, e.g. $M$. coniospora.

In the present communication we report on the ability of $M$. coniospora conidia to attract 
nematodes in relation to their attachment at specific sites on the nematode surface. Scanning electron microscopy was used to detect infection sites. Blockage of the chemoreceptors by adhered conidia was studied in regard to its influence on nematode attraction, and inhibition experiments with sugar haptens were carried out to detect any possible lectin-carbohydrate interaction.

\section{METHODS}

Organisms. The endoparasitic fungus Meria coniospora Drechsler, CBS 615.82, and the nematode-trapping Dactylaria candida (Nees) Sacc., CBS 220.54, were maintained on diluted corn meal agar (Difco, CMA 1:10, $1.5 \% \mathrm{w} / \mathrm{v}$ agar). The conidia of $M$. coniospora were washed off the plates using sterile water or buffer.

The bacteria used for attraction tests, Sarcina lutea, Pseudomonas fiuorescens, Escherichia coli and Serratia marcescens, were cultivated in nutrient broth (Difco). The bacterial-feeding nematode Panagrellus redivivus (Linn) T. Gooday, was axenically cultivated, harvested and washed as previously described (Jansson \& NordbringHertz, 1979). Two additional bacterial-feeders, Acrobeloides sp., and Mesodiplogaster sp., were maintained with associated bacteria on Nigon's agar (Sohlenius, 1973) and extracted using a Baermann funnel technique. The plant-parasitic nematodes, Aphelenchoides fragariae (Ritzema Bos) Christie, and Ditylenchus destructor Thorne, were cultivated on callus cultures and were harvested and washed as previously described (Jansson \& NordbringHertz, 1980). The plant-parasites were supplied from the 'nematode bank' at the Department of Plant and Forest Protection, Swedish University of Agricultural Sciences, Uppsala, by courtesy of Dr Bengt Eriksson.

Adhesion of conidia to nematodes. For massive infection a heavy water suspension of conidia (approx. $10^{9} \mathrm{ml}^{-1}$ ) was spread on to a dried water agar plate $\left(1.5 \%\right.$, w/v agar). After addition of nematodes (approx. $\left.3000 \mathrm{ml}^{-1}\right)$ the infection was allowed to proceed for $3 \mathrm{~h}$, unless otherwise stated. In order to estimate the percentage of adhesion of conidia to different nematode species, the nematodes were washed off the plates and stained with lactophenol blue and observed in a microscope at $125 \times$ magnification. The numbers of uninfected nematodes and nematodes infected in mouth, tail and other parts of the body were recorded. Usually $100-200$ worms were counted and were separated into males, females and larvae. The percentage of infection was then calculated. Using the same infection technique, suspensions of infected nematodes for scanning electron microscopy and attraction studies were acquired.

Attraction assay. The attraction of nematodes to fungal mycelia and to conidia was estimated with the agar plate techniques previously used (Jansson \& Nordbring-Hertz, 1979; Jansson, 1982). Attraction of nematodes to bacteria was assayed in the same way as attraction to conidia (Jansson, 1982), conidia being exchanged for bacteria. The numbers of nematodes accumulated around fungi or bacteria were counted and compared with controls. In all cases five replicate plates were used.

Scanning electron microscopy. Infected nematodes were fixed in $2.5 \% \mathrm{v} / \mathrm{v}$ glutaraldehyde in $10 \mathrm{~mm}$ buffer (MOPS, $\mathrm{pH}$ 7.2) overnight. After being washed, the material was dehydrated in an ethanol series and critical point dried in $\mathrm{CO}_{2}$. The nematodes were mounted and coated with a gold-palladium alloy and observed in a Cambridge Mark II scanning electron microscope at the Department of Structural Zoology, University of Lund, or in a Jeol $200 \mathrm{CX}$ scanning transmission electron microscope at the Department of Pathology, Malmö General Hospital.

Inhibition of adhesion. In order to investigate possible inhibition by different carbohydrates, the conidia were suspended for $24 \mathrm{~h}$ in $50 \mathrm{~mm}$ sugar solutions in distilled water or buffer (MOPS, pH 7.2, $5 \mathrm{mM}$ ). These conidia were then added to water agar plates, nematodes were added, and the whole was treated as described above for adhesion of conidia. The percentage of nematodes with adhered conidia was calculated.

Neuraminidase treatment. Specimens of the nematode $P$. redivivus were washed in $10 \mathrm{mM}$-sodium-acetate buffer, pH 5.5 , containing $154 \mathrm{mM}-\mathrm{NaCl}$ and $4 \mathrm{mM}-\mathrm{CaCl}_{2}$. The nematodes were treated for $1 \mathrm{~h}$ at $37^{\circ} \mathrm{C}$ with 125 or 250 units of neuraminidase $\mathrm{ml}^{-1}$ (Calbiochem-Behring, 500 units $\mathrm{ml}^{-1}$, EC 3.2.1.18) in the same solution. Controls with nematodes in buffer solution, and in one case with boiled enzyme, were run concurrently. After enzyme treatment the nematodes were again washed in buffer solution and added to water agar plates with conidia of $M$. coniospora. After $2-3 \mathrm{~h}$ the infected and uninfected nematodes were counted and the percentage of uninfected nematodes was calculated.

\section{RESULTS}

The precise infection sites of $M$. coniospora conidia on the nematode $P$. redivivus were studied by scanning electron microscopy. All infected nematodes were attacked in the mouth region (Fig. $1 a$ ), and the other parts of the body were uninfected, except in male worms which were also attacked at specific sites in the tail region (Fig. $1 b$ ). Conidia adhered only to the papillae, or sensory organs, of the nematodes both around the mouth and at the caudal papillae in the tail of the males (Fig. 1c). The infection of nematodes by the conidia occurred via the adhesive bud 

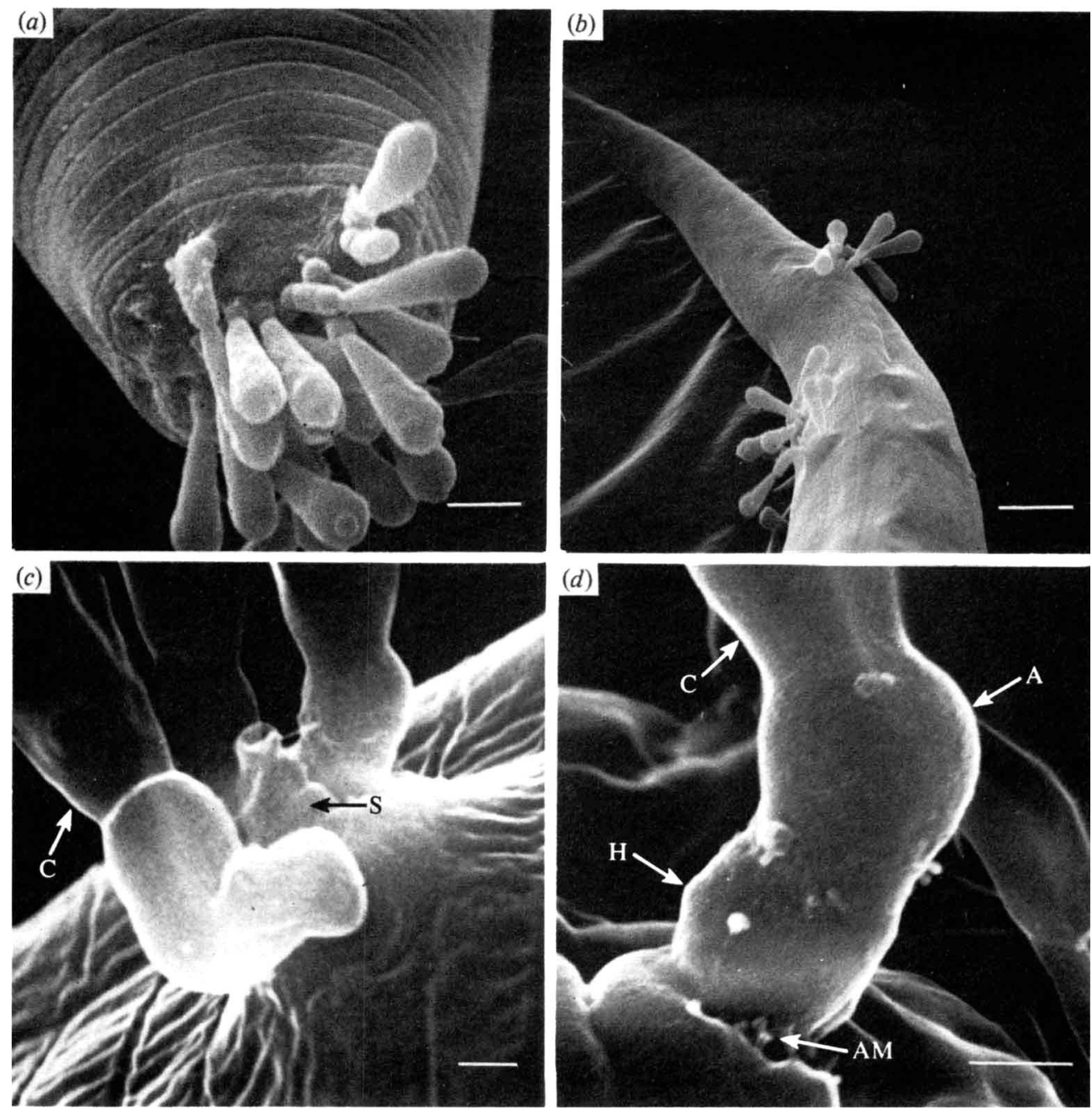

Fig, 1. Scanning electron micrographs of infections of Meria coniospora conidia on the nematode Panagrellus redivivus. (a) Mouth region heavily infected with conidia; $(b)$ part of the tail region of a male nematode with conidial infections; $(c)$ detail of conidial infection site; $(d)$ conidial infection of the nematode. A, adhesive bud of conidium; AM, anchoring materials; $\mathrm{C}$, conidium; $\mathbf{H}$, haustorium-like outgrowth; $\mathrm{S}$, sensory organ of the nematode. The bar markers represent $2 \mu \mathrm{m}$ in $(a), 5 \mu \mathrm{m}$ in $(b)$ and $0 \cdot 2 \mu \mathrm{m}$ in $(c)$ and $(d)$.

which is produced at maturity of the conidia. When the conidia are attached to the nematodes a haustorium-like outgrowth develops which seems to be anchored to the worms by some unknown material (Fig. 1d).

Infection tests with other nematode species were performed in the same manner as with $P$. redivivus. Table 1 shows the results of three bacterial-feeding and two plant-parasitic nematodes. The bacterial-feeders were infected only in the mouth region, except for males of $P$. redivivus which were also infected in the tail. In the other two nematodes feeding on bacteria, Acrobeloides sp. and Mesodiplogaster sp., males were never observed. The two plant-parasitic nematodes, $A$. fragariae and $D$. destructor, were also infected in the mouth, and in the tail of male nematodes, but these nematodes were also frequently observed to be infected in other parts of the cuticle. These results suggest different composition of the epicuticles of plant-parasitic and bacterial-feeding nematodes. 
Table 1. Infection of different nematodes by Meria coniospora conidia

Infection is expressed as a percentage of each type of nematode infected.

\begin{tabular}{|c|c|c|c|c|c|c|c|c|c|}
\hline \multirow[b]{3}{*}{ Nematode* } & \multicolumn{9}{|c|}{ Infection of: } \\
\hline & \multicolumn{3}{|c|}{ Males } & \multicolumn{3}{|c|}{ Females } & \multicolumn{3}{|c|}{ Larvae } \\
\hline & mouth & tail & body & mouth & tail & $\widehat{\text { body }}$ & mouth & tail & body \\
\hline Panagrellus redivivus (b.f.) & 96 & 89 & 2 & 96 & 0 & 4 & 96 & 0 & 4 \\
\hline Acrobeloides sp. (b.f.) & - & - & - & 95 & 0 & 0 & 95 & 0 & 0 \\
\hline Mesodiplogaster sp. (b.f.) & - & - & - & 100 & 0 & 0 & 91 & 0 & 18 \\
\hline Aphelenchoides fragariae (p.p.) & 35 & 42 & 62 & 38 & 2 & 72 & 39 & 5 & 80 \\
\hline Ditylenchus destructor (p.p.) & 13 & 60 & 73 & 42 & 0 & 89 & 46 & 0 & 72 \\
\hline
\end{tabular}

Table 2. Attraction of the nematode Panagrellus redivivus, infected and uninfected by conidia of Meria coniospora, to bacteria, mycelia and conidia

The values represent the number of attracted nematodes \pm standard error.

\begin{tabular}{lcc}
\multicolumn{1}{c}{ Attraction source } & $\begin{array}{c}\text { Infected } \\
\text { nematodes* }\end{array}$ & $\begin{array}{c}\text { Uninfected } \\
\text { nematodes }\end{array}$ \\
Conidia $(M$. coniospora $)$ & $4 \cdot 4 \pm 1 \cdot 2$ & $16 \cdot 5 \pm 3 \cdot 1$ \\
Mycelia $(D$. candida) & $3 \cdot 5 \pm 1 \cdot 4$ & $18 \cdot 3 \pm 3 \cdot 7$ \\
Bacteria $(S$. lutea $)$ & $9 \cdot 2 \pm 2 \cdot 1$ & $30 \cdot 3 \pm 5 \cdot 6$ \\
Control (average) & $1 \cdot 8 \pm 0 \cdot 5$ & $4 \cdot 8 \pm 1 \cdot 3$ \\
* $>75 \%$ of nematodes accumulated were not infected by the fungus.
\end{tabular}

In order to investigate further the role of the receptors for chemoattraction of nematodes and adhesion of conidia, two different approaches were applied: (1) blockage of the nematode chemoreceptors and its effect on attraction of nematodes, and (2) specific inhibition of the adhesion of conidia with carbohydrates.

Nematodes ( $P$. redivivus) were treated with $M$. coniospora conidia for $2-3 \mathrm{~h}$. The attraction of infected nematodes was compared with that of uninfected specimens. As attraction sources not only conidia of $M$. coniospora (Jansson, 1982) were used, but also strongly attracting mycelia of the nematode-trapping D. candida (Jansson \& Nordbring-Hertz, 1979) and a bacterial food source. The four bacterial species tested as attractants, S. lutea, P. fluorescens, E. coli and $S$. marcescens, all gave similar results. The uninfected nematodes were strongly attracted to all sources. The attraction of nematodes infected with $M$. coniospora conidia was lost (Table 2). During the experimental period the mobility of the infected nematodes appeared to be unaffected and the nematodes were moving around at random in the centre of the attraction plate. Thus, blocking of the chemoreceptors by infection with conidia abolished the attraction not only to conidia of $M$. coniospora but also to other attraction sources.

If a lectin-carbohydrate binding, similar to that described for $A$. oligospora by NordbringHertz \& Mattiasson (1979), takes place between $M$. coniospora and the nematode $P$. redivivus, then the adhesion should be inhibited by treatment of the lectin-bearing structure with sugar haptens. When the conidia were soaked in solutions of 21 carbohydrates, five of these sugars inhibited the adhesion. Table 3 shows that $N$-acetylneuraminic acid, a sialic acid, caused inhibition both in water and buffer solution. Weaker inhibition was exhibited by L-sorbose, $\mathrm{N}$ acetyl-D-galactosamine, 2-deoxy-D-galactose and L-xylose. $\mathrm{D}(+)$ Glucosamine hydrochloride, $\alpha$ $D$-galactose and $\alpha$-D-glucose, on the other hand, were ineffective in both water and buffer solutions. The following sugars tested in water solution were without effect: D-arabinose, Lfucose, $\alpha$-D-melibiose, 3- $O$-methyl- $\alpha$-D-glucopyranose, $\mathrm{D}(+)$ mannose, $\mathrm{D}$-fructose, 2-deoxy-Dglucose, $\mathrm{D}(+)$ trehalose, $\mathrm{D}$-glucose-1-phosphate, $N$-acetyl- $\beta$-D-mannosamine, $N$-acetyl-D-glucos- 
Table 3. Inhibition by means of carbohydrates of adhesion of Meria coniospora conidia to the nematode Panagrellus redivivus

$\begin{array}{llc}\quad \text { Carbohydrate } & \text { Wuffer }(50 \mathrm{~mm}) \\ N \text {-Acetylneuraminic acid } & \begin{array}{c}\text { Inhibition* of adhesion } \\ \text { by carbohydrates in: }\end{array} \\ \text { L-Sorbose } & + & - \\ N \text {-Acetyl-D-galactosamine } & + & - \\ \text { 2-Deoxy-D-galactose } & + & - \\ \text { L-Xylose } & + & - \\ \alpha \text {-D-Galactose } & + & - \\ \alpha \text {-D-Glucose } & - & - \\ \text { D }(+) \text { Glucosamine hydrochloride } & - & -\end{array}$

amine, $\alpha$-methyl-D-mannoside, lactose. These experiments indicate the localization of sialic acid to the papillae of the nematodes.

The enzyme neuraminidase causes splitting off of sialic acids. When nematodes were treated with neuraminidase, $30-33 \%$ of the enzyme-treated nematodes were uninfected by conidia, whereas in controls with buffer, and boiled enzyme, $9-13 \%$ of the worms remained uninfected. There were no differences between the enzyme concentrations used. Thus, there was a $20 \%$ decrease in attachment of conidia to the nematodes when sialic acids had been removed.

\section{DISCUSSION}

Nematophagous fungi with adhesive infection mechanisms, both nematode-trapping and endoparasitic species, seem in general to be able to infect nematodes over the whole cuticle (Barron, 1977; Nordbring-Hertz \& Stålhammar-Carlemalm, 1978). The infection of P. redivivus with conidia of $M$. coniospora was the first example of specific infection sites (Jansson, 1982). Specificity of infection sites was also confirmed for other bacterial-feeding nematodes tested. The plant-parasitic nematodes, on the other hand, were infected over the whole cuticle, indicating different composition of the outer cuticle between plant-parasitic nematodes and those which feed on bacteria. McClure \& Zuckerman (1982) studied the distribution of mannose and mannoside residues on nematode cuticles using concanavalin A and SEM. They found these carbohydrates localized to the head region of two nematode species. Himmelhoch \& Zuckerman (1978) investigated the presence of sialic acids on the cuticle of a bacterial-feeding nematode and reported no traces of such carbohydrates. However, in this case no special attention was paid to the head region. The localization of sialyl and galactosyl residues on four plant-parasitic nematodes was recently studied by Spiegel et al. (1982). Three of these nematodes showed the presence of sialic acids evenly distributed over the cuticles, whereas in one species the carbohydrate was sited only at the mouth and tail regions. In the present investigation the sialic acid $\mathrm{N}$-acetylneuraminic acid was the only carbohydrate tested which caused inhibition of conidial adhesion. As only treatment of conidia with this sugar solution caused inhibition, it is reasonable to assume that sialic acid residues on the nematode are in part responsible for the adhesion of conidia. The sialic acids should thus be localized on the papillae of the bacterialfeeding nematodes tested and on the plant-parasites the sialic acids might be distributed over the whole cuticle. This agrees well with the results of McClure \& Zuckerman (1982) and Spiegel et al. (1982) where sugars have been shown to be localized to specific sites, varying in the different species.

Neuraminidase treatment of nematodes, which splits off sialic acids, reduced infection compared to controls. This would again indicate the role of sialic acids in the adhesion of conidia to the worms. Since neither neuraminidase treatment nor sialic acid treatment of conidia completely inhibited conidial attachment, there must also be other mechanism(s) of infection. 
In nematode-trapping fungi with adhesive traps a lectin-carbohydrate interaction is involved in the capture of nematodes (Nordbring-Hertz \& Mattiasson, 1979; Mattiasson et al., 1980; Nordbring-Hertz et al., 1982). The lectin binding is considered to be a recognition step leading to further events, such as penetration of the nematode cuticle and digestion of the nematode. In $\boldsymbol{A}$. oligospora the trap lectin appears to be developmentally regulated (Nordbring-Hertz et al., 1981). The present results indicate that a similar developmentally regulated mechanism may also be important in the case of endoparasitic fungi. A lectin specific for sialic acids might be located on the adhesive buds of the conidia of $M$. coniospora and partly responsible for the adhesion to the papillae of the nematodes.

In conclusion, the adhesion of $M$. coniospora conidia to the sensory organs of the nematodes seems to block the chemoreceptors and abolish nematode attraction. The adhesion mechanism involves the localization of sialic acids on nematode sensory organs. The biochemistry behind the adhesion, e.g. the involvement of a sialic acid specific lectin on the conidia, needs further investigation.

We are grateful to Dr Claes von Meckenburg and Dr Rolf Odselius for valuable help with scanning electron microscopy. This work was supported by the Swedish Natural Science Research Council.

\section{REFERENCES}

BARRON, G. L. (1977). The Nematode-destroying Fungi. Topics in Mycobiology, no. 1. Guelph: Canadian Biological Publications.

Coomans, A. \& De Grisse, A. (1981). Sensory structures. In Plant Parasitic Nematodes, vol. III, pp. 127-174. Edited by B. M. Zuckerman \& R. A. Rohde. New York: Academic Press.

FIELD, J. I. \& WEBSTER, J. (1977). Traps of predacious fungi attract nematodes. Transactions of the British Mycological Society 68, 467-469.

Himmelhoch, S. \& ZuCKerman, B. M. (1978). Caenorhabditis briggsae: aging and the structural turnover of the outer cuticle surface and the intestine. Experimental Parasitology 45, 208-214.

JANSSON, H.-B. (1982). Attraction of nematodes to endoparasitic nematophagous fungi. Transactions of the British Mycological Society 79, 25-29.

JANSSON, H.-B. (1983). Predacity by nematophagous fungi and its relation to the attraction of nematodes. Microbial Ecology (in the Press).

JansSON, H.-B. \& NoRdBring-Hertz, B. (1979). Attraction of nematodes to living mycelium of nematophagous fungi. Journal of General Micro. biology 112, 89-93.

JANSSGN, H.-B. \& NoRdBRING-HerTZ, B. (1980). Interactions between nematophagous fungi and plantparasitic nematodes: attraction, induction of trap formation and capture. Nematologica 26, 383-389.

Mattiasson, B., Johansson, P.-A. \& NoRdBringHERTZ, B. (1980). Host-microorganism interaction; studies on the molecular mechanisms behind the capture of nematodes by nematophagous fungi. Acta chemica scandinavica B34, 539-540.

McClure, M. A., \& Zuckerman, B. M. (1982). Localization of cuticular binding sites of concanavalin A on Caenorhabditis elegans and Meloidogyne incognita. Journal of Nematology 14, 39-44.
Nordbring-Hertz, B. \& Mattiasson, B. (1979). Action of a nematode-trapping fungus shows lectinmediated host-microorganism interaction. Nature, London 281, 477-479.

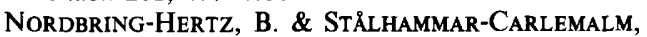
M. (1978). Capture of nematodes by Arthrobotrys oligospora, an electron microscope study. Canadian Journal of Botany 56, 1297-1307.

Nordbring-Hertz, B., Friman, E., Johansson, P.-A. \& Mattiasson, B. (1981). Host-microorganism interaction: developmentally regulated lectin-mediated capture of nematodes by nematode-trapping fungi. In Lectins - Biology, Biochemistry and Clinical Biochemistry, vol. 1, pp. 43-50. Edited by T. C. BøgHansen. Berlin: W. de Gruyter.

Nordbring-Hertz, B., Friman, E. \& Mattiasson, B. (1982). A recognition mechanism in the adhesion of nematodes to nematode-trapping fungi. In Lectins Biology, Biochemistry and Clinical Biochemistry, vol. 2, pp. 83-90. Edited by T. C. Bøg-Hansen. Berlin: W. de Gruyter.

SoHLENIUS, B. (1973). Growth and reproduction of a nematode Acrobeloides sp. cultivated on agar. Oikos 24, 64-72.

Spiegel, Y., CoHN, E. \& Spiegel, S. (1982). Characterization of sialyl and galactosyl residues on the body wall of different plant parasitic nematodes. Journal of Nematology 14, 33-39.

WARD, S. (1978). Nematode chemotaxis and chemoreceptors. In Taxis and Behavior. Receptors and Recognition, series B, vol. 5, pp. 141-168. Edited by G. L. Hazelbauer. London: Chapman \& Hall.

Wright, K. A. (1980). Nematode Sense Organs. In Nematodes as Biological Models, vol. 2, pp. 237-295. Edited by B. M. Zuckerman. New York: Academic Press. 